\title{
Performance of a Kind of Novel Z-scheme Photocatalytic Catalysts: $\mathrm{CdMoO}_{4} / \mathrm{CNTs} / \mathrm{g}-\mathrm{C}_{3} \mathrm{~N}_{4}$
}

\author{
Jifeng Guo ${ }^{1,2}$, Yuxuan Ma', Pengtao Li ${ }^{1}$, Rui Liu', Zeyang Ma1, \\ Yonghua Zhao ${ }^{2 *}$ \\ ${ }^{1}$ School of Water and Environment, Key Laboratory of Subsurface Hydrology and Ecology in Arid Areas, \\ Ministry of Education, Chang'an University, Xi'an 710054, China \\ ${ }^{2}$ Shaanxi Key Laboratory of Land Consolidation, Xi'an 710054, China
}

Received: 9 March 2020

Accepted: 9 June 2020

\begin{abstract}
Facial mixing preception method was used to prepare the $\mathrm{CdMoO}_{4} / \mathrm{CNTs} / \mathrm{g}-\mathrm{C}_{3} \mathrm{~N}_{4}$. The novel Z-scheme samples were characterized by using XRD, SEM, FT-IR, XPS, UV-vis, PL, EIS and photocurrent response. The photocatalytic activity of the catalyst was measured by degradation of tetracycline hydrochloride $(\mathrm{TCH})$ under visible light. The optimal photocatalytic degradation efficiency of $10 \mathrm{wt} \% \mathrm{CdMoO}_{4} / \mathrm{CNTs} / \mathrm{g}-\mathrm{C}_{3} \mathrm{~N}_{4}$ was up to $85.3 \%$, which was higher than $\mathrm{CdMoO}_{4}, \mathrm{CdMoO}_{4} / \mathrm{CNTs}$ and $\mathrm{g}_{-} \mathrm{C}_{3} \mathrm{~N}_{4}$. The enhanced photocatalytic performance of the heterojunction was attributed to the highly separation efficiency of photogenerated electron-hole pairs. A Z-scheme system was produced in $\mathrm{CdMoO}_{4} / \mathrm{CNTs} / \mathrm{g}-\mathrm{C}_{3} \mathrm{~N}_{4}$ with the doping of CNTs.
\end{abstract}

Keywords: photocatalytic, Z-scheme, TCH (tetracycline hydrochloride) degradation, $\mathrm{CdMoO}_{4} /$ $\mathrm{CNTs} / \mathrm{g}-\mathrm{C}_{3} \mathrm{~N}_{4}$ heterojunction

\section{Introduction}

Semiconductor photocatalytic technology was an effective way to solve the problem of energy shortage and environmental pollution [1]. It was widely used in the degradation of pollutants and hydrogen production. There were some common materials like $\mathrm{TiO}_{2}$ and $\mathrm{ZnO}$, which could only absorb the ultraviolet light because the high recombination of photogenerated electron and hole pairs [2]. In order to expand the use of photocatalysts, it was essential to develop their visible ability. In the

*e-mail: 3555898315@qq.com past years, a Z-scheme photocatalytic mechanism caused concern for its high efficiency of quantum, deep oxidation power and excellent electrons separation efficiency [3-4]. In the all solid Z-scheme photocatalysis mechanism system, solid electron mediator played an important role in charge migration. Nowadays, there were more than two kinds of semiconductor, metal and non-metal oxides and valuable materials for all solid state Z-type photocatalysis system. Most of them, such as $\mathrm{CdS} / \mathrm{Bi}_{3} \mathrm{O}_{4} \mathrm{Cl}$ [5], $\mathrm{CdS} / \mathrm{WO}_{3}$ [6], $\mathrm{ZnO} / \mathrm{Pt} / \mathrm{CdZnS}$ [7], $\mathrm{Ag} @ \mathrm{AgCl} / \mathrm{RGO}[8]$ and g- $\mathrm{C}_{3} \mathrm{~N}_{4} / \mathrm{C} / \mathrm{Bi}_{2} \mathrm{MoO}_{6} \mathrm{Z}$-Scheme composites [9], had been synthesized successfully and applied in photocatalytic degradation pollutants and water splitting. 
For its advantages of cheap, available and environmental friendly, the graphite-like carbon nitride $\left(\mathrm{g}-\mathrm{C}_{3} \mathrm{~N}_{4}\right)$ had showed outstanding performance of photocatalytic [10]. However, the fast recombination of photoinduced electrons and holes and the low surface area influenced the photocatalytic performance of bare g- $\mathrm{C}_{3} \mathrm{~N}_{4}$. Therefore, there were varieties of catalysts based on $\mathrm{g}-\mathrm{C}_{3} \mathrm{~N}_{4}$ had been explored such as $\mathrm{g}-\mathrm{C}_{3} \mathrm{~N}_{4} /$ $\mathrm{Ag}_{2} \mathrm{VO}_{2} \mathrm{PO}_{4}$ [11], $\mathrm{Bi}_{2} \mathrm{O}_{3} / \mathrm{GCN}$ [12], CQDS/g- $\mathrm{C}_{3} \mathrm{~N}_{4}$ [13] and $\mathrm{Ag} / \mathrm{AgBr} / \mathrm{g}-\mathrm{C}_{3} \mathrm{~N}_{4}[14]$ in order to avoid the above limitation. Meanwhile, novel and more efficient $\mathrm{g}-\mathrm{C}_{3} \mathrm{~N}_{4}-$ based catalysts still need to be developed.

Cadmium molybdate $\left(\mathrm{CdMoO}_{4}\right)$ is one of the interesting materials due to its excellent optical and chemical properties [15]. However, the photocatalytic activity was limited with pure $\mathrm{CdMoO}_{4}$ for low visible light response and wide band gap. As a kind of carbonaceous material [16] multi-walled carbon nanotubes (CNTs) possessed great electrons transferring ability and large surface area [17]. Most importantly, CNTs include many active pots; and it could achieve the fast separation of photo-generated electron-hole pairs and enhance the photoactivity. In the past researches, the CNTs had excellent photoactivity in the application of photocatalysis, such as $\mathrm{g}-\mathrm{C}_{3} \mathrm{~N}_{4} / \mathrm{CNTs} / \mathrm{Ag}_{3} \mathrm{PO}_{4}$ [18] and $\mathrm{g}-\mathrm{C}_{3} \mathrm{~N}_{4} / \mathrm{CNTs} / \mathrm{Bi}_{2} \mathrm{WO}_{6}[19]$.

In order to obtain an efficient photocatalyst, CNTs was induced in $\mathrm{CdMoO}_{4}$ and $\mathrm{g}-\mathrm{C}_{3} \mathrm{~N}_{4}$ by facial mixing preception method to construct a ternary heterojunction. The samples were characterized by using XRD, SEM, FT-IR, XPS, UV-vis, PL, EIS and photocurrent response. The photocatalytic activity of the catalyst was measured by degradation of tetracycline hydrochloride (TCH) under the visible light.

\section{Experiments}

\section{Preparation of $\mathrm{g}-\mathrm{C}_{3} \mathrm{~N}_{4}$}

The $\mathrm{g}-\mathrm{C}_{3} \mathrm{~N}_{4}$ was prepared through thermal condensation method [20]. $5 \mathrm{~g}$ melamine was put in a crucible with a cover and heated to $550^{\circ} \mathrm{C}$ with a heating rate of $10^{\circ} \mathrm{C} / \mathrm{min}$, then maintained at that temperature for $4 \mathrm{~h}$. After natural cooling to room temperature, the obtained products were grounded to powders with the agate bowl and yellow g- $\mathrm{C}_{3} \mathrm{~N}_{4}$ particles were collected.

\section{Preparation of CNTs $/ \mathrm{CdMoO}_{4}$}

The CNTs $/ \mathrm{CdMoO}_{4}$ composite was prepared by a hydrothermal method [16]. Firstly, $0.617 \mathrm{~g}$ $\mathrm{Cd}\left(\mathrm{NO}_{3}\right)_{2} \cdot 2 \mathrm{H}_{2} \mathrm{O}$ were dissolved in $40 \mathrm{ml}$ distilled water and $50 \mathrm{mg}$ CNTs were subsequently added into the above solution and the mixed solution were sonicated processed for $1 \mathrm{~h} .0 .484 \mathrm{~g} \mathrm{Na} \mathrm{MoO}_{4} \cdot 2 \mathrm{H}_{2} \mathrm{O}$ were dissolved in $40 \mathrm{ml}$ ethylene glycol to form transparent solution. Then, the sodium molybdate solution was added slowly into $\mathrm{Cd}\left(\mathrm{NO}_{3}\right)_{2}$-CNTs suspended solution.
Finally, the mixed solution was stirred for $30 \mathrm{~min}$ and the pasty mixture was sealed into a $100 \mathrm{ml}$ Teflonlined autoclave and maintained at $160^{\circ} \mathrm{C}$ for $6 \mathrm{~h}$. The as-prepared composites were washed by centrifugation for several times with water and absolute ethanol respectively, and desiccation at $60^{\circ} \mathrm{C}$ for $8 \mathrm{~h}$ under vacuum. Meanwhile, the bare $\mathrm{CdMoO}_{4}$ without CNTs was prepared in the same process.

\section{Preparation of $\mathrm{CdMoO}_{4} / \mathrm{CNTs} / \mathrm{g}-\mathrm{C}_{3} \mathrm{~N}_{4}$ Composite Photocatalyst}

Different ratios of $\mathrm{CdMoO} / \mathrm{CNTs} / \mathrm{g}-\mathrm{C}_{3} \mathrm{~N}_{4}$ composite photocatalysts were fabricated by a facile precipitation and mixed heating method. In a typical procedure, $0.1 \mathrm{~g} \mathrm{~g} \mathrm{C}_{3} \mathrm{~N}_{4}$ were dispersed into $20 \mathrm{ml}$ methanol and sonicated for $30 \mathrm{~min}$. A certain amount of CNTs/ $\mathrm{CdMoO}_{4}$ was added into the above suspension slowly under violent stirring, and the mixture was under subsequent continuous stirring at room temperature until the methanol was vapored. Then, the precipitate was collected and dried at $60^{\circ} \mathrm{C}$ for $5 \mathrm{~h}$. Finally, the composite was heated at $400^{\circ} \mathrm{C}$ for $2 \mathrm{~h}$ in muffle furnace after grounded. The different weight ratios photocatalysts were prepared successfully, and the weight percentage ratios of $\mathrm{CNTs} / \mathrm{CdMoO}_{4}$ to $\mathrm{g}-\mathrm{C}_{3} \mathrm{~N}_{4}$ were $3 \%, 7 \%, 10 \%, 20 \%, 30 \%, 40 \%, 50 \%$ in the precursors, respectively. The obtained different ratio $\mathrm{CdMoO}_{4} / \mathrm{CNTs} / \mathrm{g}-\mathrm{C}_{3} \mathrm{~N}_{4}$ composites were marked as $3 \mathrm{MCN}, 7 \mathrm{MCN}, 10 \mathrm{MCN}, 20 \mathrm{MCN}, 30 \mathrm{MCN}, 40 \mathrm{MCN}$ and $50 \mathrm{MCN}$, respectively.

\section{Characterization}

The crystal structures of the as-obtained samples were determined using X-ray diffract meter (XRD, Bruker/D8-advance). The microscopic morphology and size were observed by scanning electron microscopy (SEM, Hitachi FESEM-4800). The optical absorption range was investigated through diffuse reflectance spectra using a UV-vis spectrophotometer (UVvis, Evolution 220) with white $\mathrm{BaSO}_{4}$ as a reference sample. The functional groups were analyzed by fourier transformation infrared spectroscopy (FT-IR) spectrometer (Spectrum Two). X-ray photoelectron spectroscopy (XPS) was conducted to analyze the chemical elements and atoms states of the samples. Electrochemical impedance spectroscopy (EIS) and photocurrent response were obtained to realize the electrochemical property with a CHI660 D electrochemical workstation (Chen Hua Instruments, Shanghai, China). Photoluminescence (PL) was also carried out to test the charge transfer efficiency.

\section{Photocatalytic Experiment}

The photocatalytic performance of the catalysts was measured by photocatalytic degradation of $15 \mathrm{mg} / \mathrm{L}$ TCH solution under visible light irradiation. 
Firstly, $25 \mathrm{mg}$ samples were added into $50 \mathrm{~mL}$ tetracycline hydrochloride $(\mathrm{TCH})$ solution with violently magnetically stirring in a glass vessel. Then the mixture was placed in a dark room for 30 minutes to reach adsorption-desorption equilibrium between photocatalysts and TCH. Subsequently, the photocatalytic experiment was carried out under a $350 \mathrm{~W}$ Xe light irradiation with filtering short wavelength light $(\lambda<420 \mathrm{~nm})$. Compared to the catalyst, the blank sample was treated in the same condition to study the self-decomposition performance of $\mathrm{TCH}$ solution. The visible light catalytic experiment was continued for $120 \mathrm{~min}$ and $5 \mathrm{ml}$ of suspended solution was collected every $20 \mathrm{~min}$, and the mixture was centrifuged for $5 \mathrm{~min}$ at $12000 \mathrm{r} / \mathrm{min}$ to separate the residual photocatalyst. The concentration of $\mathrm{TCH}$ solution was measured by a UV-vis spectrophotometer featuring at $356 \mathrm{~nm}$ (the largest absorption wavelength of the target contaminant).

\section{Results and Discussions}

\section{Structure and Morphology Characterization}

XRD diffraction results of $\mathrm{g}_{-} \mathrm{C}_{3} \mathrm{~N}_{4}, \mathrm{CdMoO}_{4}$ and different $\mathrm{MCN}$ composites were shown in Fig. 1. The diffraction of $\mathrm{g}-\mathrm{C}_{3} \mathrm{~N}_{4}$ showed two different peaks, the weaker one at $13.1^{\circ}$ and the stronger one were at $27.4^{\circ}$. The diffraction peaks were in accordance in the (100) and (002) characteristic patterns of $\mathrm{g}-\mathrm{C}_{3} \mathrm{~N}_{4}$, respectively [21]. The characterized peaks of $\mathrm{CdMoO}_{4}$ were corresponding to the tetragonal phase of $\mathrm{CdMoO}_{4}$ (JCPDS NO:07--0209) [22], whose the peaks were observed at about $29.24^{\circ}, 32.0^{\circ}, 34.8^{\circ}, 47.98^{\circ}, 50.0^{\circ}$, $55.3^{\circ}, 58.98$ and $60.6^{\circ}$. Furthermore, that both peaks of $\mathrm{g}_{-} \mathrm{C}_{3} \mathrm{~N}_{4}$ and $\mathrm{CdMoO}_{4}$ was obvious in the all $\mathrm{MCN}$ composites characteristic patterns. It was notable that

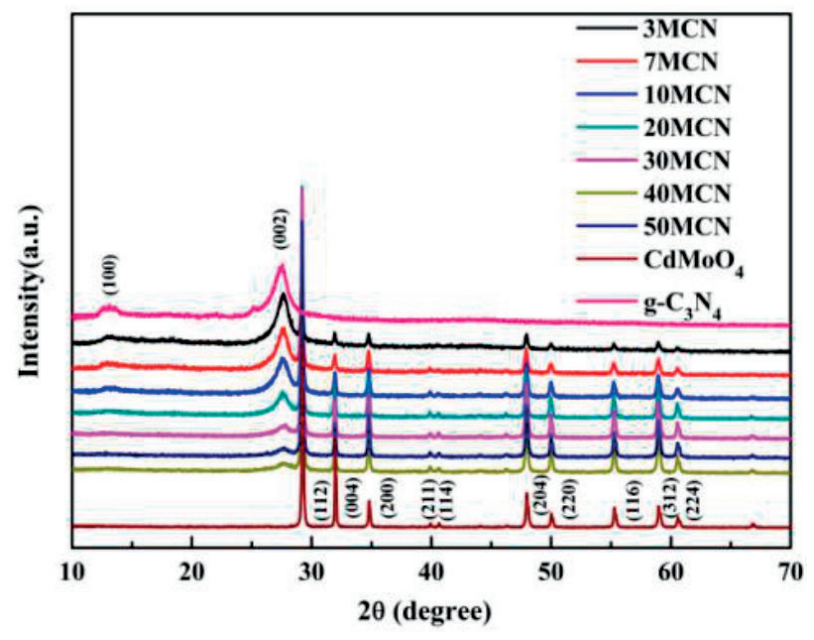

Fig. 1. The characterized patterns of $\mathrm{g}_{-} \mathrm{C}_{3} \mathrm{~N}_{4}, \mathrm{CdMoO}_{4}$ and $\mathrm{MCN}$ composites.
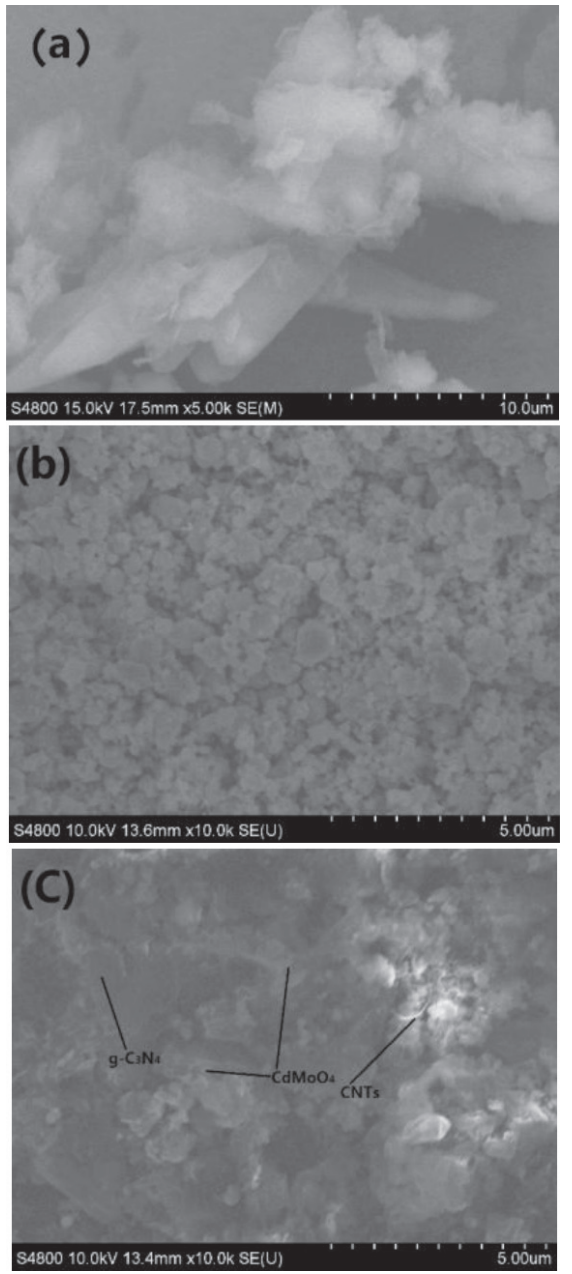

Fig. 2. SEM images of $\mathrm{g}_{-} \mathrm{C}_{3} \mathrm{~N}_{4}$ a), $\mathrm{CdMoO}_{4}$ b) and $10 \mathrm{MCN}$ c).

the peaks of $\mathrm{g}-\mathrm{C}_{3} \mathrm{~N}_{4}$ became weaker in the composites as the ratio of $\mathrm{CNTs} / \mathrm{CdMoO}_{4}$ increased.

The microstructure and morphology of $\mathrm{g}-\mathrm{C}_{3} \mathrm{~N}_{4}$, $\mathrm{CdMoO}_{4}$ and $10 \mathrm{MCN}$ composite was shown in Fig. 2. Pure $\mathrm{g}-\mathrm{C}_{3} \mathrm{~N}_{4}$ exhibited folded sheet shape in Fig. 2a). Spherical shape of $\mathrm{CdMoO}_{4}$ was dispersed

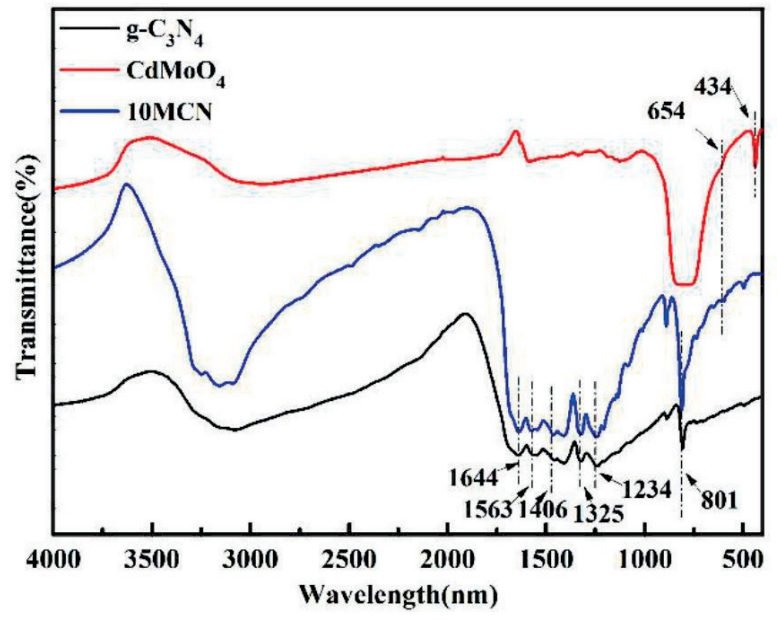

Fig. 3. FT-IR spectrums of $\mathrm{g}_{-} \mathrm{C}_{3} \mathrm{~N}_{4}, \mathrm{CdMoO}_{4}$ and $10 \mathrm{MCN}$. 
with a micro-nano meter level in Fig. 2b). And the $\mathrm{CdMoO} / \mathrm{CNTs} / \mathrm{g}-\mathrm{C}_{3} \mathrm{~N}_{4}$ scanning image was shown in Fig. 2c), cube-like CNTs were combined with $\mathrm{CdMoO}_{4}$ particles and dispersed in the $\mathrm{g}-\mathrm{C}_{3} \mathrm{~N}_{4}$ surface. It was clearly that the $\mathrm{g}-\mathrm{C}_{3} \mathrm{~N}_{4}$ sheet became thicker in the composite, which indicated the great interaction between the two semiconductors.

\section{FT-IR Results}

FT-IR results of $\mathrm{g}_{-} \mathrm{C}_{3} \mathrm{~N}_{4}, \mathrm{CdMoO}_{4}$ and $10 \mathrm{MCN}$ were shown in Fig. 3. For bare $\mathrm{g}_{-} \mathrm{C}_{3} \mathrm{~N}_{4}$, distributions of main characteristic peaks were at 1234, 1325, 1406 and $1563 \mathrm{~cm}^{-1}$, which were corresponding to the aromatic $\mathrm{C}-\mathrm{N}$ stretching vibration modes. The peak related to $\mathrm{C}-\mathrm{N}$ stretching vibration modes was appeared at $1644 \mathrm{~cm}^{-1}$, another peak at $808 \mathrm{~cm}^{-1}$ could be observed that represented the out-of-plane bending modes of heterocyclic $\mathrm{C}-\mathrm{N}$ [23]. The spectrum pattern of $\mathrm{CdMoO}_{4}$ showed two absorption peaks at $654 \mathrm{~cm}^{-1}$ and $434 \mathrm{~cm}^{-1}$, which corresponded to the O-Mo-O stretching vibration mode and Mo-O-Mo stretching vibration mode, respectively [24]. For $10 \mathrm{MCN}$, the absorption peak of $\mathrm{g}-\mathrm{C}_{3} \mathrm{~N}_{4}$ could be obviously observed, and the
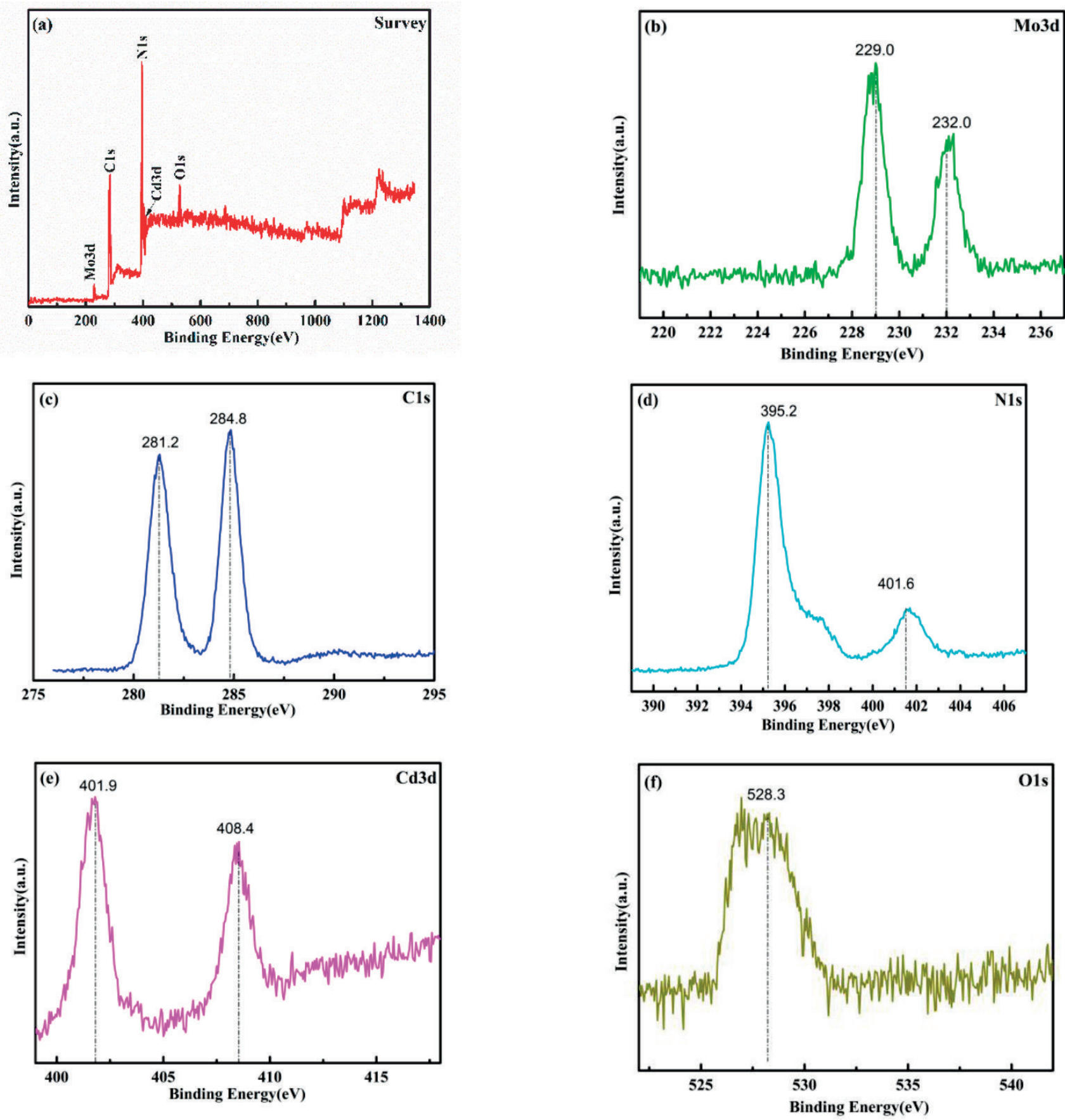

Fig. 4. XPS spectrum of $10 \mathrm{MCN}$ : survey a), Mo3d b), C1s c), N1s d), Co3d e) and O1s f). 
O-Mo-O expansion bond corresponding to $654 \mathrm{~cm}^{-1}$ could be seen. The peak corresponding to the Mo-OMo expansion bond was weak, which may be due to the low content of $\mathrm{CdMoO}_{4}$ in the heterojunction and the weak strength of this peak. The above results proved the existence of $\mathrm{g}_{-} \mathrm{C}_{3} \mathrm{~N}_{4}$ and $\mathrm{CdMoO}_{4}$ characteristics bonded in heterogeneous junction and the two materials were recombined successfully.

\section{XPS Analysis}

XPS analysis of $10 \mathrm{MCN}$ was conducted and the results were shown in Fig.4. According to the Fig. 4a), the composition elements of heterojunction included Mo, C, N, Cd and O. In the Mo3d spectra (Fig. 4b), binding energy were at 229.0 and $232.0 \mathrm{eV}$ [25]. The binding energy at 401.9 and $408.4 \mathrm{eV}$ were in accordance with the Cd symmetric peaks, which corresponded to the previous report [22]. The spectra peak of $\mathrm{Cls}$ at 281.2 and $284.8 \mathrm{eV}$ [16] corresponded to the $\mathrm{C}=\mathrm{N}-\mathrm{C}$ bond from $\mathrm{g}-\mathrm{C}_{3} \mathrm{~N}_{4}$, and $\mathrm{C}-\mathrm{C}$ bond from CNTs respectively. From the Fig. 4d), the N1s peak at $395.2 \mathrm{eV}$ attributed to the N-C-N bond [21]. The XPS analysis results were in good agreement with the XRD patterns.
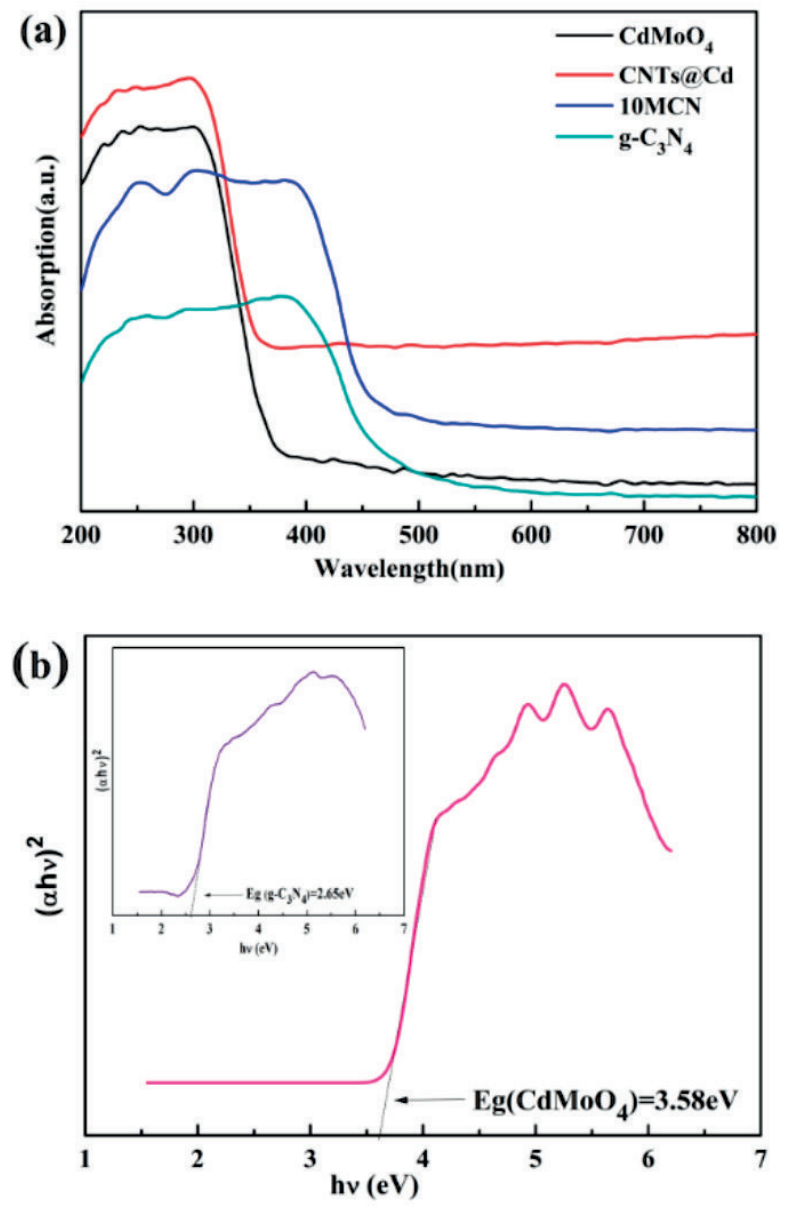

Fig. 5.UV-vis absorption spectra a) and band gap values b) of $\mathrm{g}_{-} \mathrm{C}_{3} \mathrm{~N}_{4}, \mathrm{CdMoO}_{4}$ and $10 \mathrm{MCN}$.

\section{UV-vis Analysis}

UV-vis spectra of $\mathrm{g}_{-} \mathrm{C}_{3} \mathrm{~N}_{4}, \mathrm{CdMoO}_{4}, \mathrm{CNTs} / \mathrm{CdMoO}_{4}$ and $10 \mathrm{MCN}$ were measured in the range of 200-800 $\mathrm{nm}$ and all the results were presented in Fig. 5a). Based on the previous report [26], it showed that $\mathrm{g}-\mathrm{C}_{3} \mathrm{~N}_{4}$ could absorb the UV strongly, and the absorption spectrum edge was about $470 \mathrm{~nm}$. For the pristine $\mathrm{CdMoO}_{4}$, the absorption edge was blown $365 \mathrm{~nm}$ which indicated $\mathrm{CdMoO}_{4}$ only absorbed the UV light [27]. As the introduction of $\mathrm{CNTs}, \mathrm{CNTs} / \mathrm{CdMoO}_{4}$ had stronger absorption in all light regions. As for $10 \mathrm{MCN}$ heterojunction, the visible light absorption edge got red shifted and it can utilize more range light. It proved that the visible light response was enhanced after introducing the CNTs into the $10 \mathrm{MCN}$ heterojunction.

The Kubelka-Munk equation could be used for calculating band gap (Eg) to evaluate the light utilization ability of the samples further, the equation are as following formula (1) [28].

$$
\partial(h v)=A(h v-E g)^{n / 2}
$$

In here, $\alpha, h, v, A, E g$ and $\mathrm{n}$ present the absorption coefficient, Planck constant, incident light frequency, a constant, band gap and an integer, respectively.

The value of $n$ mainly depends on the electronic transition structure of different semiconductors, where $\mathrm{n}=1$ if the band gap is a direct transition and $\mathrm{n}=4$ if the band gap is an indirect transition. After the calculation, the detailed Eg values of $\mathrm{g}-\mathrm{C}_{3} \mathrm{~N}_{4}$ and $\mathrm{CdMoO}_{4}$ were obtained, which were about $2.65 \mathrm{eV}$ and $3.58 \mathrm{eV}$, respectively (shown in Fig. 5b).

What is more, the edge potential of the valence band (VB) and conduction band (CB) could be calculated by following equation (2) and (3) [29] with the known Eg.

$$
\begin{gathered}
E_{C B}=X-E^{e}-0.5 E g \\
E_{V B}=E_{C B}+E g
\end{gathered}
$$

In these equations, $\mathrm{E}_{\mathrm{CB}}$ and $\mathrm{E}_{\mathrm{VB}}$ represents $\mathrm{CB}$ and VB edge potentials of semiconductor, respectively. $X$ is the absolute electronegativity of semiconductor that is estimated by the geometric mean of the electronegativity of the constituent atoms. Furthermore, $E^{e}$ is the energy of free electrons on the hydrogen scale $(\sim 4.5 \mathrm{eV})$. According to the Ref [30-31], the $X$ value of $\mathrm{CdMoO}_{4}$ and $\mathrm{g}_{-} \mathrm{C}_{3} \mathrm{~N}_{4}$ were $6.16 \mathrm{eV}$ and $5.64 \mathrm{eV}$, respectively. After the above calculations, we could see the $E_{C B}$ of $\mathrm{CdMoO}_{4}$ and $\mathrm{g}-\mathrm{C}_{3} \mathrm{~N}_{4}$ were $-0.13 \mathrm{eV}$ and $-1.2 \mathrm{eV}$; and the $E_{V B}$ of them were $3.45 \mathrm{eV}$ and $1.45 \mathrm{eV}$, respectively.

According to these results, it was obvious that the visible light absorption performance of $10 \mathrm{MCN}$ was considerably enhanced compared with pure $\mathrm{CdMoO}_{4}$ and $\mathrm{g}-\mathrm{C}_{3} \mathrm{~N}_{4}$, it showed the heterojunction could utilize more visible light. The enhanced visible light absorption performance involved high separation efficiency 
between photogenerated electron-hole pairs by the introducing of CNTs.

\section{Electrochemical Analysis}

The photocurrent response of $\mathrm{g}_{-} \mathrm{C}_{3} \mathrm{~N}_{4}, \mathrm{CdMoO}_{4}$ and $10 \mathrm{MCN}$ were displayed in Fig. 6. The high photocurrent response intensity represented rapid separation of photogenerated electron-hole pairs [23]. From the Fig. 6a), the photocurrent response of $10 \mathrm{MCN}$ showed the higher intensity than bare g- $\mathrm{C}_{3} \mathrm{~N}_{4}$ and $\mathrm{CdMoO}_{4}$. It indicated the high separation efficiency of photogenerated electron-hole pairs with
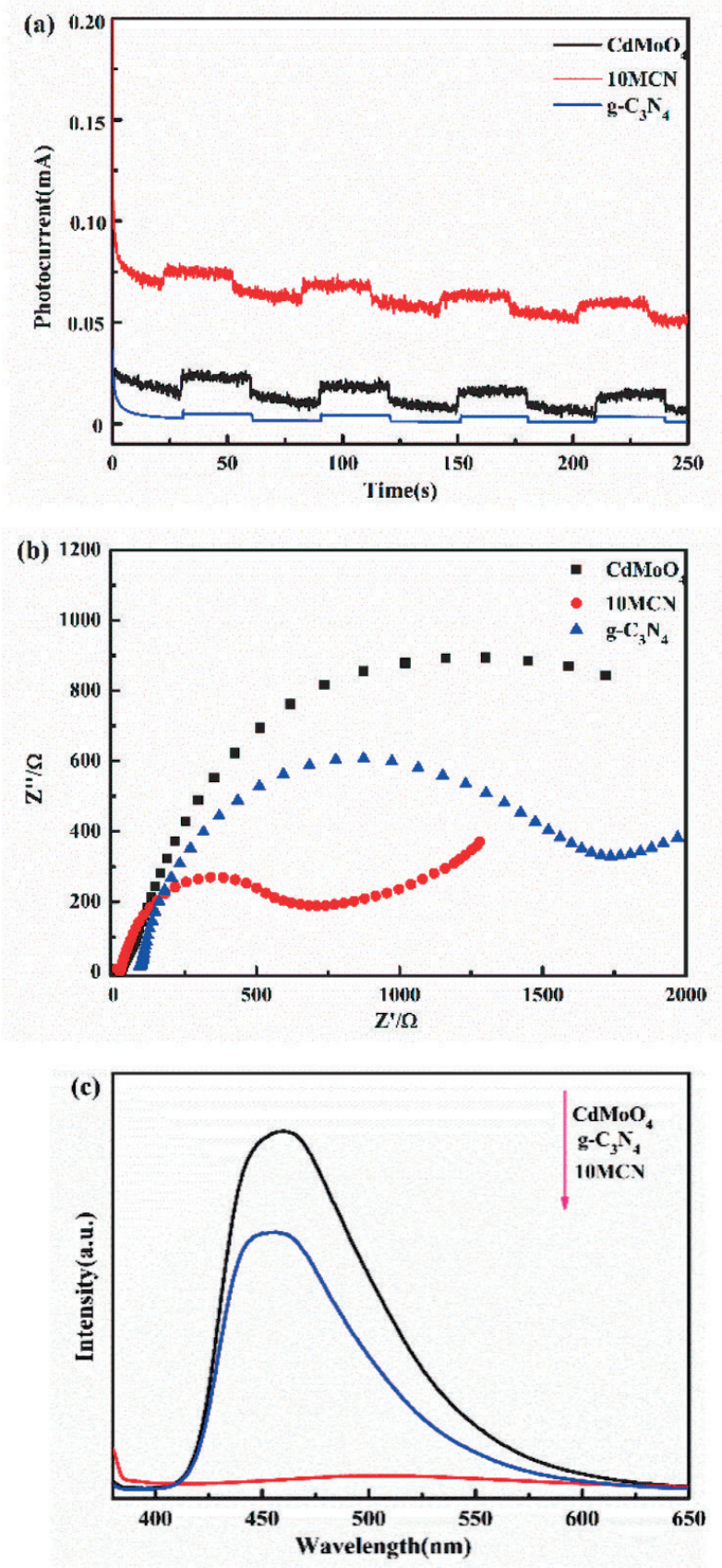

Fig. 6. Photocurrent response EIS of $\mathrm{g}_{-} \mathrm{C}_{3} \mathrm{~N}_{4}, \mathrm{CdMoO}_{4}$ a) and $10 \mathrm{MCN} \mathrm{b}$ ) of $\mathrm{g}-\mathrm{C}_{3} \mathrm{~N}_{4}, \mathrm{CdMoO}_{4}$ and $10 \mathrm{MCN} \mathrm{c}$ ). the heterojunction. The electrochemical impedance spectroscopy (EIS) of $\mathrm{g}_{-} \mathrm{C}_{3} \mathrm{~N}_{4}, \mathrm{CdMoO}_{4}$ and $10 \mathrm{MCN}$ were characterized, Nyquist plots of these samples were shown in Fig. 6b). It was known that the smaller arc radius represented a lower electron transfer resistance and the charge transfer efficiency was improved in the process of photocatalytic degradation [32]. It was seen that the interfacial charge-transfer resistance of $10 \mathrm{MCN}$ was greatly decrease than the bare $\mathrm{LaCoO}_{3}$ and $\mathrm{g}-\mathrm{C}_{3} \mathrm{~N}_{4}$, and it would enhanced the carrier transport efficiency that was attributed to the formation of the heterojunction.

To further certify the electrochemical property, photoluminescence (PL) was tested and the result was shown in Fig. 6c). The PL spectra results displayed the separation of charge and the recombination of electronhole pairs. Higher spectra peaks usually represented higher recombination of electron-hole pairs and a lower photocatalytic activity [33]. The absorption intensity of $10 \mathrm{MCN}$ is lower than that of the two pure semiconductors, indicating that the suppression of electron-hole recombination has occurred in the heterojunction.

The above measured results revealed the high charge separation efficiency and more suppression of electronhole pairs from the recombination in the $\mathrm{CdMoO}_{4} /$ CNTs/g- $\mathrm{C}_{3} \mathrm{~N}_{4}$ heterojunction. It was proved that the CNTs-inserted heterojunction could improve the quantum efficiency and had an influence on the charge transferring, and enhanced photocatalytic activity further.

\section{Photocatalytic Activity Analysis}

The photocatalytic performances of the as-prepared samples were measured by degradation of TCH solution under visible light, the experimental results was shown in Fig. 7. These could be concluded that (i) $\mathrm{TCH}$ contaminant was stable. It is too hard for them to self-decompose under visible light irradiation without any photocatalysts from the blank experiment. (ii) For pure $\mathrm{CdMoO}_{4}$ and $\mathrm{g}-\mathrm{C}_{3} \mathrm{~N}_{4}$, the degradation rate was unsatisfied with $8.15 \%$ and $17.4 \%$ of TCH was degraded respectively. While, $\mathrm{CNTs} / \mathrm{CdMoO}_{4}$ had stronger photodegradation efficiency that was $30.4 \%$, which indicated the introduction of CNTs played an important role in catalytic activity. (iii) $\mathrm{CdMoO}_{4} / \mathrm{CNTs} / \mathrm{g}-\mathrm{C}_{3} \mathrm{~N}_{4}$ heterojunction showed higher catalytic activity than $\mathrm{CNTs} / \mathrm{CdMoO}_{4}$ and $\mathrm{g}-\mathrm{C}_{3} \mathrm{~N}_{4}$, the photocatalytic rate was enhanced gradually with $\mathrm{CNTs} / \mathrm{CdMoO}_{4}$ loading ratio from $3 \%$ to $10 \%$. The optimal degradation rate was up to $85.3 \%$ with $10 \mathrm{MCN}$. (iv) The photocatalytic activity decreased with further increasing the doping ratio of $\mathrm{CNTs} / \mathrm{CdMoO}_{4}$, which could lead the contacted area decreased and the charge transferring restrained.

To further confirm the photocatalytic activity was improved efficiently heterojunction, the kinetic constant [34] was introduced that calculated by the pseudo-firstorder reaction rate equation of $-\ln \left(\mathrm{c} / \mathrm{c}_{0}\right)=\kappa \mathrm{t}$, where $\mathrm{c}_{0}$ 

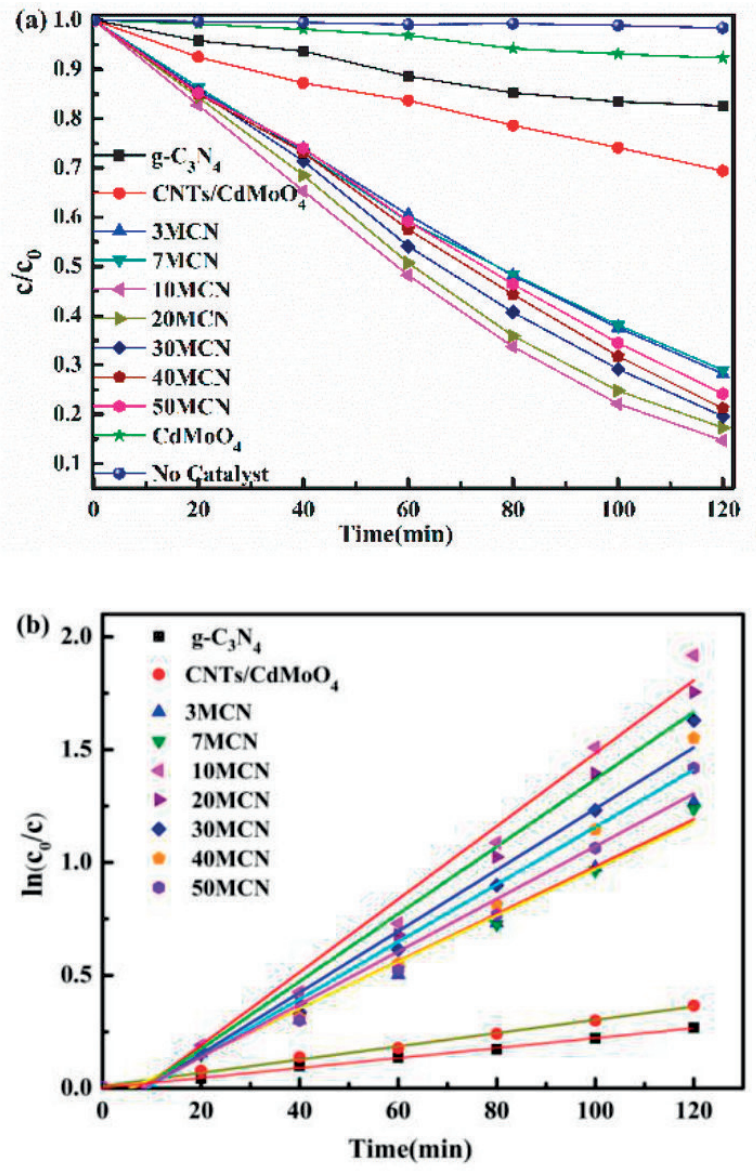

Fig. 7. Photocatalytic degradation efficiency of TCH with g- $\mathrm{C}_{3} \mathrm{~N}_{4}, \mathrm{CNTs} / \mathrm{CdMoO}_{4}$ and $\mathrm{MCN}$ composites a), the first-order kinetics of photodegradation with $\mathrm{g}_{-} \mathrm{C}_{3} \mathrm{~N}_{4}, \mathrm{CNTs} / \mathrm{CdMoO}_{4}$ and MCN composites b).

represents the initial concentration of $\mathrm{TCH}, \mathrm{c}$ is the $\mathrm{TCH}$ concentration at the time $t$, and $\mathrm{K}$ is the kinetic constant. From the calculation results, it was shown that the heterojunction had prominent photocatalytic degradation performance compared with pure catalysts. The kinetic constant of TCH degradation of $10 \mathrm{MCN}$ $\left(\kappa=0.01617 \mathrm{~min}^{-1}\right)$ was about 10.43 times of pure $\mathrm{g}-\mathrm{C}_{3} \mathrm{~N}_{4}\left(\kappa=0.00155 \mathrm{~min}^{-1}\right)$ and about 5.39 times of pure $\mathrm{CNTs} / \mathrm{CdMoO}_{4}\left(\kappa=0.003 \mathrm{~min}^{-1}\right)$, which could be inferred the modification with $\mathrm{CNTs} / \mathrm{CdMoO}_{4}$ improved the photocatalytic performance dramatically under light irradiation. The specific results were shown in Fig. 7b).

To explore the stability and recyclable use of the heterojunction, cycling degradation experiments including using, recovering, washing and reusing for 5 times were carried out, and the results showed that photocatalytic activity of $10 \mathrm{MCN}$ was deteriorated after 5 cycling due to the occurrence of light corrosion, but the heterojunction still exhibited high photocatalytic activities. After 5 cycles of experiments, the 10MCN heterojunction was still displayed excellent catalytic activity (TCH degradation was over $80 \%$ ), which proved that the heterojunction had relatively high stability against light corrosion reaction.

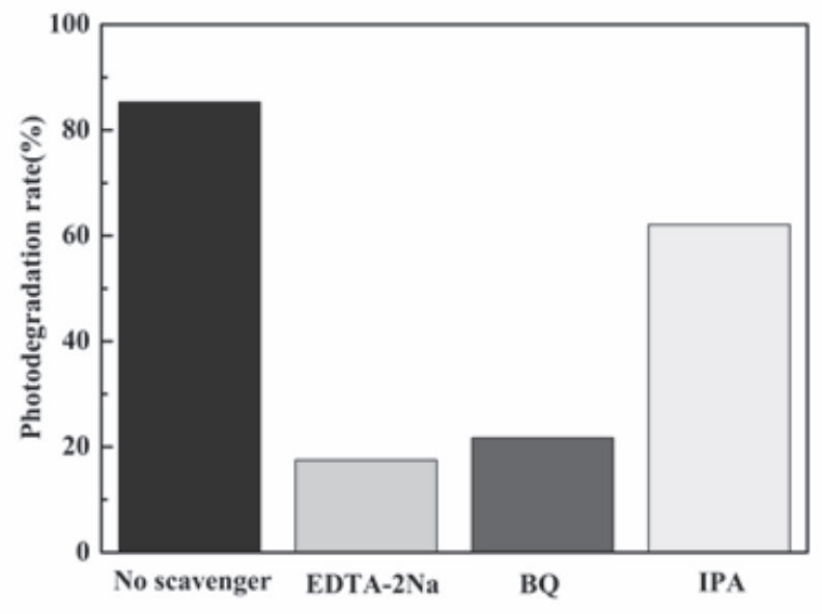

Fig. 8. Active species trapping experiment of $10 \mathrm{MCN}$.

\section{Active Species Trapping Experiment}

In order to explore the main active materials at the photocatalytic degradation process of $120 \mathrm{CL}$ heterojunction, the trapping experiment was carried out. The scavengers include 1, 4-benzoquinone (BQ), disodium ethylenediamine tetraacetic acid (EDTA) and 2-propanol (IPA), which were used to scavenge the superoxide radicals $\left(\cdot \mathrm{O}_{2}^{-}\right)$, holes $\left(\mathrm{h}^{+}\right)$and hydroxyl radicals $(\bullet \mathrm{OH})$, respectively. The details were adding $0.5 \mathrm{mmol}$ scavengers to test how scavengers influenced the quality of photocatalytic under the same experiment condition. The experiment result was shown as Fig. 8. It was concluded that the photo degradation efficiency of TCH decreased remarkably with the addition of BQ and EDTA. In addition, it changed with the addition of IPA. When IPA was added to the reaction system, the degradation rate of TCH was about $60 \%$, while, when EDTA-2Na and BQ were added in the system, respectively, the degradation rate of $\mathrm{TCH}$ reached about $15 \%$ and $20 \%$, respectively. Therefore, the main active species were $\mathrm{h}^{+}$and $\bullet \mathrm{O}_{2}^{-}$, and the $\bullet \mathrm{OH}$ was the secondary active species.

\section{Photocatalytic Mechanism Discussion}

The $\quad \mathrm{CdMoO}_{4} / \mathrm{CNTs} / \mathrm{g}-\mathrm{C}_{3} \mathrm{~N}_{4}$ photocatalytic mechanism could be concluded according to the above the result of the experiment. The Z-scheme photocatalytic system was formed due to the insertion of CNTs. The difference of VB and CB edge potentials between $\mathrm{g}-\mathrm{C}_{3} \mathrm{~N}_{4}$ and $\mathrm{CdMoO}_{4}$ could offer the condition to achieve the separation of photo-generated electronhole pairs. At the same time, the recombination of both could be restricted by the existence of heterojunction. In the system, the charge transfer and separation were faster in the occurrence of CNTs. When light irradiated to the heterojunction, both $\mathrm{g}-\mathrm{C}_{3} \mathrm{~N}_{4}$ and $\mathrm{CdMoO}_{4}$ absorbed photon powder and they were excited rapidly themselves to produce $\mathrm{e}^{-}$and $\mathrm{h}^{+}$. As an important 


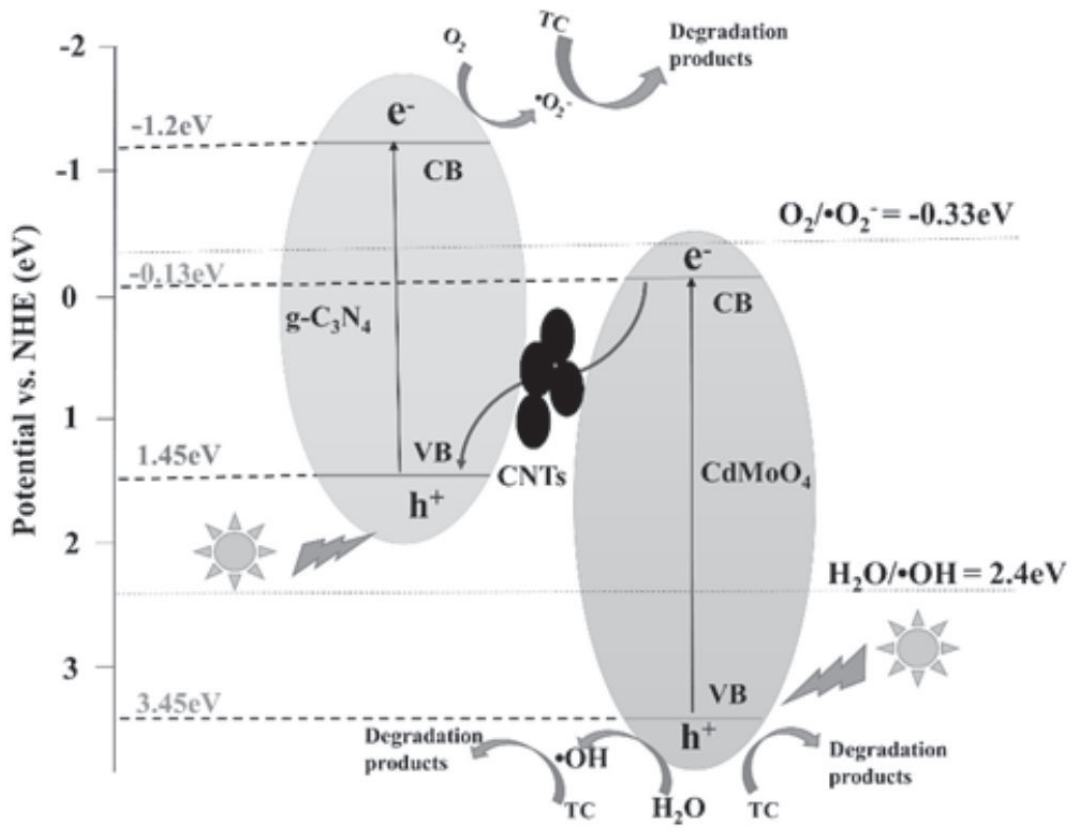

Fig. 9. Z- scheme photocatalytic mechanism of $\mathrm{CdMoO}_{4} / \mathrm{CNTs} / \mathrm{g}-\mathrm{C}_{3} \mathrm{~N}_{4}$ heterojunction.

bridge, CNTs had an important influence on the charge migration. The $\mathrm{e}^{-}$in the $\mathrm{CB}$ of $\mathrm{CdMoO}_{4}$ could move quickly to the $\mathrm{VB}$ of $\mathrm{g}-\mathrm{C}_{3} \mathrm{~N}_{4}$ by the electron transfer bridge. As a result, $\mathrm{e}^{-}$was reserved in the $\mathrm{CB}$ surface of $\mathrm{g}_{-} \mathrm{C}_{3} \mathrm{~N}_{4}, \mathrm{~h}^{+}$was reserved in the $\mathrm{VB}$ of $\mathrm{CdMoO}_{4}$. Subsequently, the $\mathrm{CB}$ edge potential of $\mathrm{g}-\mathrm{C}_{3} \mathrm{~N}_{4}$ was more negative than the standard redox potential $\mathrm{E}^{\theta}$ $\left(\mathrm{O}_{2} / \bullet \mathrm{O}_{2}^{-}\right)\left(-0.33 \mathrm{~V}\right.$ vs. NHE), which could react with $\mathrm{O}_{2}$ to generate $\cdot \mathrm{O}_{2}^{-}$by this channel. At the same time, the VB edge potential of $\mathrm{CdMoO}_{4}$ was less positive than the standard redox potential $\mathrm{E}^{\theta}\left(\mathrm{H}_{2} \mathrm{O} / \cdot \mathrm{OH}\right)(2.4 \mathrm{eV}$ vs. $\mathrm{NHE}$ ), which could react with $\mathrm{H}_{2} \mathrm{O}$ to $\bullet \mathrm{OH}$. Rely on the oxidation activity of $\bullet \mathrm{O}_{2}^{-}, \cdot \mathrm{OH}$ and $\mathrm{h}^{+}, \mathrm{TCH}$ molecules could be easily oxidized into $\mathrm{CO}_{2}, \mathrm{H}_{2} \mathrm{O}$ and other simple products. Corresponding Z-scheme photocatalytic mechanism in $\mathrm{CdMoO} / \mathrm{CNTs} / \mathrm{g}-\mathrm{C}_{3} \mathrm{~N}_{4}$ heterojunction was displayed in Fig. 9.

\section{Conclusions}

A novel Z-scheme $\mathrm{CdMoO}_{4} / \mathrm{CNTs} / \mathrm{g}-\mathrm{C}_{3} \mathrm{~N}_{4}$ heterojunction was obtained by facile mixed precipitation method. CNTs were successfully introduced to enhance the charge transferring efficiency. The elements compose analysis indicated the heterojunction included $\mathrm{CdMoO}_{4}, \mathrm{CNTs}$, and g- $\mathrm{C}_{3} \mathrm{~N}_{4}$ without any impurity. SEM images showed the interaction was achieved and great crystallization in the heterojunction. The optimal photocatalytic degradation rate of TCH was up to $85.3 \%$ with $10 \mathrm{MCN}$ under visible light irradiation. It was explored that the kinetic constant of TCH degradation by $10 \mathrm{MCN}$ photocatalyst was about 5.39 times of that by $\mathrm{CNTs} / \mathrm{CdMoO}_{4}$ and about 10.43 times of that by pure $\mathrm{g}-\mathrm{C}_{3} \mathrm{~N}_{4}$, and the heterojunction still showed highly photocatalytic performance after 5 cycle using. The mechanism study revealed that the inserted-CNTs had an important influence on charge migration as a transferring bridge. It was concluded that the Z-scheme photocatalytic system in the $\mathrm{CdMoO}_{4} / \mathrm{CNTs} / \mathrm{g}-\mathrm{C}_{3} \mathrm{~N}_{4}$ heterojunction improved its photocatalytic activity under visible light. This work would provide a facile and effective approach for fabricating a high efficiency photocatalyst.

\section{Acknowledgements}

This research has been supported by the Fund Project of Shaanxi Key Laboratory of Land Consolidation (2019-JC03), Shaanxi Natural Science Basic Research Program (2019JM-429), and Chang'an University students' innovation program (S201910710242).

\section{Conflict of Interest}

The authors declare no conflict of interest.

\section{References}

1. NI M., LEUNG MKH., LEUNG DYC. A review and recent developments in photocatalytic water-splitting using $\mathrm{TiO}_{2}$ for hydrogen production. Renewable and Sustainable Energy Reviews 11 (3), 401, 2007.

2. CHEN Z.L., WANG W.L., ZHANG Z.G. High-Efficiency Visible-Light-Driven $\quad \mathrm{Ag}_{3} \mathrm{PO}_{4} / \mathrm{AgI} \quad$ Photocatalysts: Z-SchemePhotocatalytic Mechanism for Their Enhanced Photocatalytic Activity. The Journal of Physical Chemistry C 117 (38), 19346, 2013. 
3. CHEN B.C., SHEN Y., WEI J.H. Research progress on g- $\mathrm{C}_{3} \mathrm{~N}_{4}$-based Z-scheme photocatalytic system. Acta Phys. Chim.sin, 32 (6), 1371, 2016.

4. ZHOU P., YU J.G., JARONIEC MIETEK All-solid-state Z-scheme photocatalytic systems. Adv Mater 26 (29), 4920, 2014.

5. CHEN H.N., CHE G.B., JIANG E.H. A novel Z-Scheme $\mathrm{CdS} / \mathrm{Bi}_{3} \mathrm{O}_{4} \mathrm{Cl}$ heterostructure for photocatalytic degradation of antibiotics: Mineralization activity, degradation pathways and mechanism insight. Journal of the Taiwan Institute of Chemical Engineers, 91, 224, 2018.

6. ZHANG L.J., LI S., LIU B.K. Highly Efficient CdS-WO Photocatalysts Z-Scheme Photocatalytic Mechanism for Their Enhanced Photocatalytic H2 Evolution under Visible Light. ACS Catal. 4 (10), 3724, 2014.

7. ISIMJAN T.T., MAITY P., LLORCA J. Comprehensive Study of All-Solid-State Z-Scheme Photocatalytic Systems of $\mathrm{ZnO} / \mathrm{Pt} / \mathrm{CdZnS}$. ACS Omega. 2 (8), 4828, 2017.

8. MIN U.L., HE G.Q., XU Q.J. Self-assembled encapsulation of graphene oxide/ $\mathrm{Ag} @ \mathrm{AgCl}$ as a Z-scheme photocatalytic system for pollutant removal. J. Mater. Chem. A 2 (5), 1294, 2014.

9. MA T.J., WU J., MI Y.D. Novel Z-Scheme g- $\mathrm{C}_{3} \mathrm{~N}_{4} / \mathrm{C} @$ $\mathrm{Bi}_{2} \mathrm{MoO}_{6}$ composite with enhanced visible-light photocatalytic activity for $\beta$-naphthol degradation. Separation and Purification Technology. 183, 54, 2017.

10. WANG X.C., MAEDA KAZUHIKO, THOMAS AREN, A metal-free polymeric photocatalyst for hydrogen production from water under visible light. Nat Mater 8 (1), 76-, 2009.

11. ZHANG T.T., SHAO X., ZHANG D.F., Synthesis of direct Z-scheme g- $\mathrm{C}_{3} \mathrm{~N}_{4} / \mathrm{Ag}_{2} \mathrm{VO}_{2} \mathrm{PO}_{4}$ photocatalysts with enhanced visible light photocatalytic activity. Separation and Purification Technology, 195, 332, 2018.

12. ZHANG L., WANG G., XIONG Z. Fabrication of flowerlike direct $\mathrm{Z}$-scheme $\beta-\mathrm{Bi}_{2} \mathrm{O}_{3} / \mathrm{g}-\mathrm{C}_{3} \mathrm{~N}_{4}$ photocatalyst with enhanced visible light photoactivity for Rhodamine B degradation. Applied surface science, 436, 162, 2018.

13. HONG Y.Z., MENG Y.D., ZHANG G.Y. Facile fabrication of stable metal-free CQDs/g- $\mathrm{C}_{3} \mathrm{~N}_{4}$ heterojunctions with efficiently enhanced visible-light photocatalytic activity. Separation and Purification Technology 171, 229, 2016.

14. YANG Y.X., GUO W., GUO Y.N. Fabrication of Z-scheme plasmonic photocatalyst $\mathrm{Ag} @ \mathrm{AgBr} / \mathrm{g}-\mathrm{C}_{3} \mathrm{~N}_{4}$ with enhanced visible-light photocatalytic activity. J Hazard Mater 271, 150, 2014.

15. XU J.J., WU M.M., CHEN M.D. A one-step method for fabrication of $\mathrm{CdMoO}_{4}$-graphene composite photocatalyst and their enhanced photocatalytic properties. Powder Technology. 281, 167, 2015.

16. WANG S.H., ZHOU S.Q. Photodegradation of methyl orange by photocatalyst of $\mathrm{CNTs} / \mathrm{P}-\mathrm{TiO}_{2}$ under UV and visible-light irradiation. J Hazard Mater 185 (1), 77, 2011.

17. ADEL A ISMAIL,Mesoporous $\mathrm{PdO}-\mathrm{TiO}_{2}$ nanocomposites with enhanced photocatalytic activity. Applied Catalysis B: Environmental, 117-118, 67, 2012.

18. WANG W.W., WANG L., LI W.B. Fabrication of a novel g- $\mathrm{C}_{3} \mathrm{~N}_{4} /$ Carbon nanotubes $/ \mathrm{Ag}_{3} \mathrm{PO}_{4} \mathrm{Z}$-scheme photocatalyst with enhanced photocatalytic performance. Materials Letters. 234, 183, 2019.

19. JIANG D.L., MA W.X., XIAO P. Enhanced photocatalytic activity of graphitic carbon nitride/carbon nanotube/ $\mathrm{Bi}_{2} \mathrm{WO}_{6}$ ternary $\mathrm{Z}$-scheme heterojunction with carbon nanotube as efficient electron mediator. J Colloid Interface Sci 512 693, 2018.
20. CHEN F. DI,Two-dimensional heterojunction photocatalysts constructed by graphite-like $\mathrm{C}_{3} \mathrm{~N}_{4}$ and $\mathrm{Bi}_{2} \mathrm{WO}_{6}$ nanosheets: Enhanced photocatalytic activities for water purification. Journal of Alloys and Compounds, 694, 193, 2017.

21. OU M., ZHONG Q., ZHANG S.L. Synthesis and characterization of $\mathrm{g}-\mathrm{C}_{3} \mathrm{~N}_{4} / \mathrm{BiVO}_{4}$ composite photocatalysts with improved visible-light-driven photocatalytic performance. Journal of Sol-Gel Science and Technology, 72 (3), 443, 2014.

22. ADHIKARI RAJESH, MALLA SHOVA, GYAWALI GOBINDA Synthesis, characterization and evaluation of the photocatalytic performance of $\mathrm{Ag}-\mathrm{CdMoO}_{4}$ solar light driven plasmonic photocatalyst. Materials Research Bulletin 48 (9), 3367, 2013.

23. XIU Z.L., BO H., WU Y.Z. Graphite-like $\mathrm{C}_{3} \mathrm{~N}_{4}$ modified $\mathrm{Ag}_{3} \mathrm{PO}_{4}$ nanoparticles with highly enhanced photocatalytic activities under visible light irradiation. Applied Surface Science. 289, 394, 2014

24. EGHBILI-ARANI MOHAMMAD, POURMASOUD SAEID, AHMADI FARHAD Optimization and detailed stability study on coupling of $\mathrm{CdMoO}_{4}$ into $\mathrm{BaWO}_{4}$ for enhanced photodegradation and removal of organic contaminant. Arabian Journal of Chemistry, 2018.

25. LIU Y.D., REN L., QI X. One-step hydrothermal fabrication and enhancement of the photocatalytic performance of $\mathrm{CdMoO}_{4} / \mathrm{CdS}$ hybrid materials. RSC Advances 4 (17), 8772, 2014.

26. LV J., DAI K., ZHANG J. Facile synthesis of Z-scheme graphitic- $\mathrm{C}_{3} \mathrm{~N}_{4} / \mathrm{Bi}_{2} \mathrm{MoO}_{6}$ nanocomposite for enhanced visible photocatalytic properties. Applied Surface Science, 358, 377, 2015.

27. MOSTAFA H.M., MADDAHFAR MAHNAZ., SOBHANI-NASAB A. Novel silver-doped $\mathrm{CdMoO}_{4}$ synthesis, characterization, and its photocatalytic performance for methyl orange degradation through the sonochemical method, J Mater Sci: Mater Electron. 27, 474, 2016.

28. HAO R., XIAO X., ZUO X.X. Efficient adsorption and visible-light photocatalytic degradation of tetracycline hydrochloride using mesoporous $\mathrm{BiOI}$ microspheres. J Hazard Mater 209-210, 137, 2012.

29. SONG S., HONG F.Y., HE Z.Q. $\mathrm{AgIO}_{3}$-modified AgI/ $\mathrm{TiO}_{2}$ composites for photocatalytic degradation of p-chlorophenol under visible light irradiation. J Colloid Interface Sci 378 (1), 159, 2012.

30. MOUSAVI MITRA, HABIBI-YANGJEH AZIZ, Novel magnetically separable $\mathrm{g}^{-} \mathrm{C}_{3} \mathrm{~N}_{4} / \mathrm{Fe}_{3} \mathrm{O}_{4} / \mathrm{Ag}_{3} \mathrm{PO}_{4} / \mathrm{Co}_{3} \mathrm{O}_{4}$ nanocomposites: Visible-light-driven photocatalysts with highly enhanced activity. Advanced Powder Technology, 28 (6), 1540, 2017.

31. ZHANG H., CHENG G. Enhanced visible light photocatalytic activity of $\mathrm{CdMoO}_{4}$ microspheres modified with AgI nanoparticles. Catalysis communication, 86, 124, 2016.

32. XU L., LI H.N., YAN P.C. Graphitic carbon nitride/BiOCl composites for sensitive photoelectrochemical detection of ciprofloxacin. J Colloid Interface Sci, 483, 241, 2016.

33. WANG R.L., XIE T., SUN Z.Y. Graphene quantum dot modified $\mathrm{g}-\mathrm{C}_{3} \mathrm{~N}_{4}$ for enhanced photocatalytic oxidation of ammonia performance. RSC Advances, 7 (81), 51687, 2017.

34. GUO W.Y., WU P., JIANG D.M. Synthesis of $\mathrm{AgBr} @ \mathrm{Bi}_{2} \mathrm{O}_{3}$ composite with enhanced photocatalytic performance under visible light. Journal of Alloys and Compounds, 646, 437, 2015. 
